\title{
Japan reviews first guidelines for gene therapy trials
}

Tokyo. Japan last week laid the foundations for a system to regulate gene therapy by releasing guidelines compiled by a scientific committee of the Ministry of Health and Welfare. But clinical trials (see below) are not imminent: the report avoids assigning authority for final approval of gene therapy experiments, and nothing can be done until the Ministry of Education, Science and Culture, which is responsible for university hospitals, clarifies its position on use of the technique.

As expected, the guidelines prohibit its use on reproductive cells because of the impact on future generations, and they say the technique should be applied only against terminal illnesses such as brain tumours, AIDS and cancer for which no effective remedy exists. They call for review of protocols by internal review boards in hospitals and medical research institutes. The boards will be overseen by the ministry which, in turn, will be advised by a committee of specialists similar to the Recombinant DNA Advisory Committee of the US National Institutes of Health. But the committee's authority remains unclear.

Some Japanese newspapers and scientists have interpreted the guidelines as delegating most decision-making to the individual internal review boards and to the head of the hospital or institute. Kunio Yagi, director of the privately funded Institute of Applied Biochemistry in Gifu Prefecture, says that he and researchers at Nagoya University have already asked the chairman of the university's internal review board, a former student of Yagi's, to examine their preliminary plans for clinical trials on a technique for introducing interferon genes into brain cells to treat brain tumours.

Yagi hopes to complete experiments on nude mice within three months and to win approval for human clinical trials "within this year". Once he has obtained the board's approval, he does not anticipate difficulty in clearing the central government committee "provided we have the consent of the patient and our technique is scientifically acceptable and safe".

But Masaaki Terada, director of the National Cancer Centre Research Institute and one of the members of the committee that wrote the guidelines, anticipates a more comprehensive review. "It is my understanding that all gene therapy experiments will be discussed by the committee of specialists after [they have been reviewed by] the institutional committees", he says.

Masanori Fukushima of Aichi Cancer Centre, a vocal critic of the medical research system, believes that the guidelines on informed consent are flawed because they stipulate that consent can be obtained from patients orally. Without written forms such as are required in the United States, he says, it will be impossible for review committees to know if consent was really obtained.

The Ministry of Education, Science and Culture, which oversees Japan's universities, including Nagoya University, has yet to make its position clear. Yagi says the education ministry is "quite relaxed" about the issue and that it will leave the decision to individual universities. But others expect the committee of specialists to play an important role because of the small number of scientists in Japan who are knowledgeable about gene therapy and the ethical, social and legal issues raised by the new techniques.

The guidelines point to a need to win public understanding of gene therapy and the importance of conducting business openly, but they offer little advice on how this can be done. Meetings of academic and government committees are typically conducted in private.

David Swinbanks

\section{AIDS patients are first in line}

Tokyo. The first clinical trials of gene therapy in Japan are likely to involve AIDS patients and to be carried out by a private company. Mitsuru Miyata, editor of the newsletter Nikkei Biotechnology, predicts that the blood product manufacturer Midori Juji (Green Cross Corporation) will be first on the basis of the worldwide marketing rights it holds for a gene therapy treatment for AIDS developed by Viagene Inc. of San Diego, California.

Japan's Ministry of Health and Welfare, which regulates the pharmaceutical industry, is concerned about the safety of retrovirus vectors used in gene therapy because of the risk of cancer. But Viagene's vector system, carrying the full-length copy of the HIV envelope protein, has already been approved in the United States, a fact that is expected to ease its path through the Japanese ministry. Funds for developing the gene therapy guidelines came from the ministry's anti-AIDS campaign, and thus it seems likely that the first clinical trials will involve AIDS patients.

\section{NIH to support embryo bank for mice and rabbits}

Washington. Researchers would gain access to the increasing number of genetically altered strains at reasonable cost and without restrictions on their use under a plan by the US National Institutes of Health (NIH) to create a repository of frozen embryos of genetically altered rodents and rabbits.

NIH has allocated \$1 million for the repository, an accompanying inventory and another facility, possibly in a separate location, that would develop new and improved cryo-preservation techniques, particularly for freezing mouse sperm.

Grant applications are being sought from commercial breeders and non-profit enterprises, colleges, medical centres and universities with the necessary in-house expertise. Requests must be limited to not more than $\$ 350,000$ in direct costs for the first year.

"We're not trying to develop something from scratch here", says Lance Liotta, deputy director for intramural research at NIH. The facility would preserve the flood of newly discovered strains that have no commercial value but may be of interest to researchers outside the laboratories in which they were developed. At present, the task of maintaining and distributing these strains rests with the researcher.

Judy Vaitukaitis, director of the National Center for Research Resources, which is providing the funding, says that the repository would provide researchers with frozen embryos or animals "probably at less than cost". Although researchers funded by NIH will be given priority, the repository will be open to researchers with other sources of research support.

The initiative is a "step in the right direction", says Janet Rossant of the Samuel Lunenfeld Research Institute in Toronto, Canada, who is concerned about its emphasis on cryopreservation as a means of maintaining the resource. Cryopreservation is "only part of the story", she says, and is unlikely to replace the need to keep strains that are in continuous demand (which would include some of the so-called 'gene knockout' mice) as active breeding colonies. Having to breed sufficient animals for an experiment from frozen embryos can build in a delay of six months or more into a research programme, she says, and not all laboratories, if supplied with frozen embryos, would have the technical knowledge to perform the necessary embryo transfer procedures.

The deadline for proposals is 23 June, with the awards to be made after two rounds of scientific review before the close of the current fiscal year, which ends on 30 September. 